\title{
Malignant Extrahepatic Bile Duct Neoplasm
}

National Cancer Institute

\section{Source}

National Cancer Institute. Malignant Extrahepatic Bile Duct Neoplasm. NCI Thesaurus.

Code C7483.

A primary or metastatic malignant neoplasm that affects the extrahepatic bile ducts.

Representative examples include carcinoma and sarcoma. 